\title{
Emotional Sharing and the Extended Mind
}

León, Felipe; Szanto, Thomas; Zahavi, Dan

Published in:

Synthese

DOI:

10.1007/s11229-017-1351-x

Publication date:

2019

Document version

Peer reviewed version

Citation for published version (APA):

León, F., Szanto, T., \& Zahavi, D. (2019). Emotional Sharing and the Extended Mind. Synthese, 196(12), 48474867. https://doi.org/10.1007/s11229-017-1351-x 


\title{
Forthcoming in Synthese. Please quote from published version. The final publication is avail- able at Springer via http://dx.doi.org/ 10.1007/s11229-017-1351-x
}

\section{Emotional Sharing and the Extended Mind}

\section{Felipe León ${ }^{1}$, Thomas Szanto ${ }^{1}$ and Dan Zahavi ${ }^{1}$}

\begin{abstract}
This article investigates the relationship between emotional sharing and the extended mind thesis. We argue that shared emotions are socially extended emotions that involve a specific type of constitutive integration between the participating individuals' emotional experiences. We start by distinguishing two claims, the Environmentally Extended Emotion Thesis and the Socially Extended Emotion Thesis (Section 1). We then critically discuss some recent influential proposals about the nature of shared emotions (Section 2). Finally, in Section 3, we motivate two conditions that an account of shared emotions ought to accommodate: (i) Reciprocal Other-awareness, and (ii) Integration. Consideration of (ii) and discussion of relational accounts of joint attention, lead us to the proposal that a construal of socially extended emotions in terms of a constitutive integration of the participating individuals' experiences is more promising than proposals that simply appeal to various forms of social situatedness, embeddedness, or scaffolding.
\end{abstract}

Keywords: Shared emotions; extended mind; extended emotions; joint attention; interpersonal identification.

\section{Beyond Affective Internalism}

Research on shared emotions and on the extended mind has been for the most part conducted in isolation from each other. In this article, we explore the intersection of these two research domains, and argue that shared emotions are socially extended emotions that involve a specific type of consti-

\footnotetext{
${ }^{1}$ Center for Subjectivity Research, Department of Media, Cognition and Communication, University of Copenhagen. Karen Blixens Plads 8, 2300 København S, Danmark.
} 
tutive integration between the participating individuals' emotional experiences. We start by considering how emotions figure in recent literature on the extended mind, and we distinguish two claims, the Environmentally Extended Emotion Thesis and the Socially Extended Emotion Thesis. In Section 2 we critically discuss some recent influential proposals about the nature of shared emotions. Section 3 motivates two conditions that an account of shared emotions ought to accommodate: (i) Reciprocal Other-awareness, and (ii) Integration. Consideration of (ii) and discussion of relational accounts of joint attention, lead us in Section 4 to the conclusion that a construal of socially extended emotions in terms of a constitutive integration of the involved individuals' experiences is more promising than proposals that simply appeal to various forms of social situatedness, embeddedness, or scaffolding.

The last two decades have seen a rapidly growing and developing cross-disciplinary body of work advocating some version of the Extended Mind Thesis. In a nutshell, what unites these various approaches is the claim that certain cognitive or mental processes are not confined within the locus of their psychophysical realization, but rather extend beyond the natural confines of the body and incorporate some external entities, be it physical utensils, technological devices or even other individuals, supra-individual systems, or groups. Within this paradigm, it has by now become customary to distinguish three different trends, depending on how they specify the vehicles constituting or realizing so-called 'coupled', 'integrated' or 'socially distributed' cognitive systems. ${ }^{2}$ Roughly, 'first-wave' accounts championed the view that certain cognitive or mental processes that extend into the environment of individual organisms do so by means of cultural artifacts or technological devices (maps, notebooks, etc.). These accounts mostly drew on the functional parity or similarity between the role of internal and external factors in the constitution of cognition.

However, as the 'parity principle' (Clark and Chalmers 1998) and its functionalist credentials increasingly came under the lash, 'second-wave' approaches set out to stress the differences and eventually the complementarity, rather than the functional parity, of intra- and extra-organismic vehicles of cognition. Moreover, by focusing on the various socio-cognitive practices involved, these approaches also stressed the dynamic integration of intra- and extra-mental entities, thus aiming at a process-oriented version of the account (Menary 2007; Wilson \& Clark 2009; Rowlands 2010; Sutton 2010). Finally, 'third wave' accounts (Kirchhoff 2012) take an even more liberal or radical stance on the project of extending the (individual) bounds of the mental. Typically drawing on enactivist approaches to cognition, they argue that cognition often not only involves social inter-

\footnotetext{
${ }^{2}$ First-, second- and third-wave construals are typically presented if not as exclusive at least as substitutive accounts (cf. Menary 2007, 2010).
} 
action but also relies upon complex collective, cultural or institutional practices, norms and conventions (e.g., legal systems), which, qua social affordances, enable, enhance or even co-constitute individual cognition, thereby allowing for socially extended minds (Tollefsen 2006; Gallagher and Crisafi 2009; Krueger 2011; Huebner 2011; Kirchhoff 2012; Cash 2013; De Jaegher 2013; Gallagher 2013).

What about emotions? Do arguments for the Extended Mind Thesis carry over to affective processes, including bodily feelings and emotional experiences? In other words, can emotions extend beyond the boundaries of human organisms or even beyond the purview of individuals? Is it possible to defend a version of what might be called the Extended Emotion Thesis?

At first, this might seem like a surprising question. After all, even the co-originator of the Extended Mind Thesis has baulked at extending it to phenomenal consciousness (Clark 2009). ${ }^{3}$ On that background, the very question might seem settled from the outset. However, a number of recent contributions have championed the view that, in certain cases at least, phenomenal consciousness might indeed extend beyond the skin of individuals (Wilson 2004; Kiverstein and Farina 2012; Zawidski 2012; Loughlin 2013; Rowlands 2015; cf. also Ward 2012). When applied to emotions, this idea delivers the Extended Emotion Thesis. On a first characterization, which is in line with first-wave accounts of the extended mind paradigm, the claim that the phenomenal character of some emotional experiences are extended entails an externalist view about the vehicles and not merely about the (cognitive or evaluative) contents of those states. The Extended Emotion Thesis could thus be characterized as a form of what has been called - in contrast to "content externalism"-_vehicle externalism" (Rowlands 2003). It entails putting pressure on the idea that every phenomenally conscious state is spatially located inside the subject who has or undergoes it (Rowlands 2003). However, even if tempted by this approach, one reason for holding onto both internalism and individualism in the case of emotions might be that we, in an obvious sense, 'feel' emotions inside our own bodies. We tend to describe feelings and passions with intra-bodily, often cardiovascular, metaphors, such as 'heart clenching', 'butterflies in the stomach', 'blood freezing in the veins'. Moreover, emotions are often intimately linked with embodied (motoric, facial, vocal, etc.) expressions. But if "the body [is] the theatre of emotions" (Damasio 1994, 155), how could emotions extend beyond the skin and the skull of an individual?

Interestingly, some recent theories of emotion have taken this challenge head-on, shifting towards more extended and enactivist approaches (Colombetti 2014; Colombetti and

\footnotetext{
${ }^{3}$ For an internalist criticism of the extended consciousness claim, see Horgan and Kriegel 2008.
} 
Krueger 2014; Colombetti and Roberts 2015; for review, see Krueger and Szanto 2016), and also towards more social frameworks (Parkinson et al. 2005; von Scheve and Salmela 2014; Slaby 2014; Krueger 2014; 2016; Sullivan 2015). One might point here to the contribution of (i) material, artificial and technological tools (diaries, wedding rings, music, venues and sites, scripts, etc.), (ii) other individuals or sets of individuals (caretakers, romantic partners, crowds, groups, communities, etc.), their emotion-expressive and embodied features (smiles, caresses, gestures, dancing), or symbolic or communicative interactions (conversations, etc.), or (iii) even more complex structural, systemic or cultural tools, including so-called 'emotional climates' or diachronically robust 'emotional cultures' (habits, conventions, rituals, socio-economic factors, etc.). ${ }^{4}$ For our purposes, and to narrow the field somewhat, it is relevant to distinguish two versions of the Extended Emotion Thesis. ${ }^{5}$ One is the claim that a subject's emotions can extend to and incorporate environmental objects and structures, such as rings, notebooks, a particular location, etc. Call this the Environmentally Extended Emotion Thesis. This thesis has received some attention in the increasingly growing literature on emotional extension (Roberts 2015; Colombetti and Krueger 2015; Carter et al. 2016). The other claim, which has received less attention ${ }^{6}$ and on which we shall be focusing, is that a subject's emotion can extend to and incorporate another subject's emotion. Call this the Socially Extended Emotion Thesis. In this paper, we will defend a specific version of this latter thesis.

It has recently been argued that the phenomenal character of any experience has two components, a qualitative character and a subjective character (cf. Kriegel 2009: 8). Whereas the qualitative character in the case of an emotional experience would include, for instance, the hedonic tone, the subjective character pertains to the fact that the experience doesn't merely feel like something, rather, it feels like something for me (cf. Zahavi \& Kriegel 2016). The claim primarily to be defended in the following is that the subjective character of an individual's emotional

\footnotetext{
${ }^{4}$ As this list makes evident, any comprehensive investigation of the Extended Emotion Thesis would have to consider a whole series of interrelated phenomena. Compare, for instance, emotions that are merely triggered or enhanced by social factors with emotions that are more robustly structured by social scaffolding. Clearly, a case where my distress is enhanced by the distress of five other people in a waiting room, who also missed their transatlantic flight, must be distinguished from the case where one feels embarrassment as the result of unwanted social attention. The latter must on its part be distinguished from a consideration of the 'enculturation' of many of our emotions, such as shame, guilt, or embarrassment (Parkinson et al. 2005; Cole et al. 2006). Whereas, say, embarrassment qua intrinsically social emotion might be constitutively dependent upon the existence of a concrete social relation, contrition or patriotism might be felt in the absence of concrete others, even if their formation and acquisition are constitutively dependent upon specific socio-cultural configurations (Tracey et al. 2007).

${ }^{5}$ For a similar distinction, see Krueger 2014.

${ }^{6}$ A few noticeable exceptions include Krueger 2014; Slaby 2014; and Stephan et al. 2014. However, as we shall see, these proposals exhibit some shortcomings when it comes to specifying the precise criteria for social extension.
} 
experience can extend to and incorporate the subjective character of another individual's emotional experience, such that both stand in a relationship of constitutive integration.

To be sure, emotions cover a broad range of phenomena, and a more comprehensive defense of the Extended Emotions Thesis would need to make it clear which type of emotions (e.g., bodily affects, existential feelings, moods, temperaments, sentiments, etc.) are at stake. Moreover, a crucial step in arguing for emotional extension, involves a specification of the components or aspects of emotions that are supposed to be extended. These could include the emotion-regulative, the cognitive or the appraisal aspect, the neurophysiological, motivational and behavioral component, the expressive aspect, the phenomenal aspect, etc. (cf. Scherer 2005; Gross 2002). Different authors have argued for different claims (see Krueger and Szanto 2016). In this paper, we will focus on the extension of the experiential or phenomenal aspect of (shared) garden-variety type emotions (such as anger, fear, grieving, etc.) — an extension that might seem particular controversial.

Now, neither version of the Extended Emotion Thesis has met universal approval. Echoing the alleged coupling-constitution objection to the standard Extended Mind Thesis (Adams and Aizawa 2008), one worry has been that "an extended-emotion thesis potentially confuses the claim that the environment makes a causal contribution to a mental process with the more ontologically demanding claim that it is a constituent part of it" (Griffiths and Scarantino 2009, 448). Although some might argue that the coupling-constitution objection has already been convincingly rebutted by several authors (Clark 2008, 2010; Menary 2010; Rowlands 2010; Kagan and Lassiter 2013), it is still important to carefully distinguish causal coupling from proper constitutive integration.

Consider, for example, phenomena such as the "contagious euphoria or panic of a crowd" (Stephan et al. 2014, 77), or the "contagious demagogue infecting the range of [one's] emotional repertoire" (Slaby 2014, 42), or the somewhat diffuse notion of 'emotional atmospheres' and 'climates' (de Rivera and Páez 2007). Such cases fall in a quite different category than, say, cases of romantic couples, caretaker-infant pairs, or other strongly cohesive groups. One reason why it would be important to insist on the crucial difference between these two ranges of cases is that the causal coupling typical of emotional contagion lacks the deeper constitutive synchronic and diachronic integration that is distinctive of shared emotions. Moreover, the feeling of togetherness characterizing the latter, where the other subject is experientially registered as an other with whom one shares an emotion, doesn't seem to play a similar role in emotional contagion. In emotional 
contagion and other forms of affective crowd dynamics I am causally affected (and infected) by the states of somebody else and as a result come to experience the state as my own. I do not experience the emotion as ours, as one that we are having (Zahavi 2015). Even if (and let us emphasize the if) the accusation concerning a coupling-constitution fallacy might be appropriate in some cases, it is far from obvious, as we shall argue in more detail below, that it would also be pertinent in the case of shared emotions.

\section{Joint ownership, fusion and token identity}

In previous publications, all three of us have mined and explored insights regarding the link between collective intentionality, communal experiences and shared emotions that can be found in early phenomenology (e.g., Husserl, Scheler, Walther, Stein, etc.) (León \& Zahavi 2016; Szanto 2015, 2016a, 2016b, forthcoming; Zahavi 2016; Zahavi \& Salice 2017). Although our present aim is systematic and not historical, we will make productive use of ideas found in phenomenology. In this section we will proceed by critically discussing some proposals that like ours engage with phenomenology, but which, in our view, misconceive the nature of shared emotions. ${ }^{7}$

In his article "Merleau-Ponty on shared emotions and the joint ownership thesis" Krueger argues that Merleau-Ponty in his Sorbonne Lectures on child psychology defends a claim concerning the "ontology of certain early experiences," namely the view that two subjects can simultaneously be said to share the numerically same episode of experience. Krueger labels this view, the joint ownership thesis. According to Krueger, Merleau-Ponty was led to this view because of his dissatisfaction with the individualism of classical psychology and its ensuing difficulties with addressing the problem of other minds (Merleau-Ponty 1964, 114). In his criticism, Merleau-Ponty proposed that our understanding of others might become less enigmatic if one postulated an initial state of undifferentiation and took the beginning of psychogenesis to be a state where the child is unaware of itself and the other as different beings. In this first phase, there is, on Merleau-Ponty's view, not one individual over against another, "but rather an anonymous collectivity, an undifferentiated group life" (Merleau-Ponty 1964, 119). Krueger takes this claim to exemplify Merleau-Ponty's own endorsement of the view that the infant is coupled experientially to the

\footnotetext{
${ }^{7}$ To be sure, there are a number of other contemporary authors who have engaged in thorough analyses of emotional sharing. First and foremost, one should mention here Gilbert $(2002 ; 2014)$ and Salmela $(2012 ; 2014$; Salmela \& Nagatsu 2016). Concerning Gilbert, as shall become clear in the following, our account significantly diverges from her normativist one. For a more detailed criticism of Gilbert's account of emotional sharing, see Szanto forthcoming. As for Salmela, and this will become clearer below (Section 3), we consider our account complementary to his.
} 
caregiver in a state of phenomenal undifferentiation (Krueger 2013, 513-514). The task Krueger then sets himself is to motivate the plausibility of this joint ownership thesis. His primary strategy is to point to a variety of developmental research that suggests that infant and caregiver function as a coupled social system. Of particular importance is the so-called mutual affect regulation, where "infants and caregivers together establish a synchrony of emotion and expression within sequences of interaction" (Krueger 2013, 518), thereby allowing the infant to feel and experience in ways that would otherwise not be possible.

More specifically, Krueger argues that the infant's experience and expression of positive affect requires the participation of an attuned adult who constructs and regulates the affect for and with the child, for which reason the affect can be said to be inherently dyadic (Krueger 2013, 519). Insofar as the affect remains a constituent of the caregiver's experience as well, it is jointly-owned and the caregiver can be said to enter "into the infant's experience as a joint subject" (Krueger 2013, 521). In short, Krueger's fundamental claim is that insofar as the infant has experiences that can only emerge within the confines of the infant-caregiver system as a whole, the infant and caregiver can be said to share the same episode of experience (Krueger 2013, 524). Something similar might also hold true in the case of adults. After all, co-regulation happens whenever "both partners are responsive to mutual influence" (Krueger 2011, 645), and also adults have emotions that they could not have on their own, but only in the presence of others.

Krueger is well aware of the ontological implications of such a view. As he writes,

In cases of collective emotions, a token emotion extends across multiple subjects; here, one emotion is collectively realized by multiple participants. The possibility of collective emotions is philosophically intriguing because it challenges the common intuition that the ontology of emotions is such that they can only be realized by individuals (Krueger 2016, 269).

Let us consider more carefully, what it might mean to say that two (or more) individuals are sharing the numerically same experience. Obviously, the proposal isn't simply that emotions of different individuals can target the same object and ascribe it the same meaning. What the joint ownership thesis must be taken to imply is that it is possible to literally share the very same episode of experiencing. But can such a view be defended? We do not think that empirical findings regarding affect co-regulation support such a view. Consider the case of a sadistic rapist whose enjoyment feeds off the terror of the victim and where the terror of the victim isn't simply brought about by the terrible ordeal but is modulated and intensified by the rapist's delight. What the rapist experiences 
and what the victim experiences are in this case bound together. They could not have had these experiences on their own. To that extent, one might, if one will, talk about the rapist and the victim as a coupled social system, but it is hard to make sense of the idea that they should share the very same episode of experiencing.

More generally speaking, this also holds true for cases of infant-adult interaction. When engaging in a tight coupling with the infant, the adult is not suddenly reduced to an infantile level of experiencing. As various classical phenomenologists have pointed out, we should not forget the impact of temporality. To suggest that two people might share the identically same episode of experiencing (and thereby have the very same experience) seems to ignore in a rather fundamental way the historicity of our experiential life, the fact that what we have experienced in the past influences our current experiences. Here is how Schutz puts it:

The postulate, therefore, that I can observe the subjective experience of another person precisely as he does is absurd. For it presupposes that I myself have lived through all the conscious states and intentional Acts wherein this experience has been constituted. But this could only happen within my own experience and in my own Acts of attention to my experience. And this experience of mine would then have to duplicate his experience down to the smallest details, including impressions, their surrounding areas of protention and retention, reflective Acts, phantasies, etc. But there is more to come: I should have to be able to remember all his experiences and therefore should have had to live through these experiences in the same order that he did; and finally I should have had to give them exactly the same degree of attention that he did. In short, my stream of consciousness would have to coincide with the other person's, which is the same as saying that I should have to be the other person (Schutz 1967, 99; cf. Husserl 1976, § 83).

According to this criticism, the only way two people could share one and the same experience would be if they ceased being two and became one. Were that-per impossibile - to happen, one might further doubt whether it would any longer make sense to talk of sharing-since the plurality that the latter term arguably references (it doesn't make that much sense to say that I am sharing something with myself) would be gone.

Defenders of what might be called the token identity approach to shared emotions have more ammunition available, however. Krueger's proposal is inspired by Merleau-Ponty. A somewhat related account can also be found in a number of publications by Hans Bernhard Schmid, 
though he takes his inspiration from another classical phenomenologist, Scheler. Here is a central quote from Wesen und Formen der Sympathie:

The father and the mother stand beside the dead body of a beloved child. They feel in common the 'same' sorrow, the 'same' anguish. It is not that A feels this sorrow and B feels it also, and moreover that they both know they are feeling it. No, it is a feeling-in-common. A's sorrow is in no way 'objectual' for B here, as it is, e.g. for their friend C, who joins them, and commiserates 'with them' or 'upon their sorrow'. On the contrary, they feel it together, in the sense that they feel and experience in common, not only the self-same value-situation, but also the same keenness of emotion in regard to it. The sorrow, as value-content, and the grief, as characterizing the functional relation thereto, are here one and identical (Scheler 2008, 12-13, translation modified).

Schmid has interpreted this passage in support of a token identity account of shared emotions. As Schmid points out, whereas it might be relatively obvious what sharing means when it concerns objects such as a toothbrush, a cab, a cake, a bottle of wine or an apartment, it is less clear what exactly sharing means when applied to mental states. Whereas sharing in the former cases isn't simply a question of sharing objects of the same type or qualitative identity, but a question of sharing the numerical identical object, i.e., the same very token, many are committed to ontological and epistemological individualism when it comes to mental states. Ontological individualism states that mental states are necessarily owned, they are necessarily the states of somebody, and this somebody has to be an individual. In short, only individuals can be subjects of mental states. By contrast, epistemological individualism states that individuals have a privileged access to their own mental states, a direct access that provides them with a special kind of first-person authority regarding their own mental life, whereas they lack such an access to the mental states of others (Schmid $2009,72,74)$. Because of this joint commitment, it is then widely assumed that people cannot literally share a token experience. Rather, when people share an experience, what this really means is that each individual has his or her own token of the same type of experience (and in addition some accompanying mutual knowledge) (Schmid 2009, xv, 69). Schmid rejects this account and instead defends the view that mental states can be shared in the straightforward sense of the term:

there is a sense in which it is literally true that when a group of people has an emotion, there is one feeling episode, one phenomenal experience in which many agents participate. Group emo- 
tions are shared feelings. Shared feelings involve some "phenomenological fusion". They are "shared" in the strong straightforward sense in which there is one token affective state in which many individuals take part (Schmid 2014a, 9)

On Schmid's construal, in the case discussed by Scheler, the parents do not merely have emotions of the same type or matching individual feelings. Rather "while both individuals experience a feeling of grief, there are not two feelings involved in this case, but only one. The parents' feeling of grief is numerically identical" (Schmid 2009, 69).

In the process of articulating and defending this view, Schmid stipulates a number of requirements that an account of shared emotions must be able to meet:

Firstly, it has to be compatible with basic forms of individual self-awareness. People do not have to mistake themselves for another, or feel completely dissolved in some group consciousness in order to share a feeling. Secondly, it has to be compatible with the knowledge that any feeling one takes to be shared might not actually be shared at all. Thirdly, it has to leave room for the experience of (partial) separateness of our conscious lives. Not all feelings are shared. And ultimately, it has to conform to the experience that very often (if not always), the sharedness of a feeling is a matter of the qualitative difference between the individual contributions (Schmid 2009, 79).

Let us focus on the fourth requirement, which Schmid also calls the difference condition $(2009,79)$. Consider the case of a shared feeling of joy after a successful performance of a symphony. The composer, the musicians and the audience are all sharing one and the same joy, but this is not to deny that the exuberance of the composer, the contentment of the oboist, and the delight of a member of the audience are qualitatively different (Schmid 2009, 81-82). But how can this be reconciled with the token identity claim? Schmid realizes that some might think that there is an obvious contradiction here, but he claims that the following consideration will dissolve the tension: On Schmid's account, the what-it-is-likeness of emotional sharing is necessarily a what-it-is-like-for-us (Schmid 2014b, 14). As we have already seen, Schmid interprets this as amounting to a form of phenomenal fusion, namely as the experience of one plural self. Importantly, he does not conceive of this plural self as some kind of larger singular 'I', but precisely as a self with more than one participant. Schmid even argues that such a phenomenal fusion leaves room for an awareness of interpersonal difference, though he emphasizes that the difference in question is not between distinct 
subjects, but between different parts of a unified whole. Schmid consequently tends to think of group emotions as one whole to which individuals contribute their parts (Schmid 2014a, 10). Although the numerical identity of the feeling does not preclude differences, the differences in question are not between numerically different feelings, but between aspects of one and the same feeling. Just as the wheels and the frame can be different parts of one and the same bicycle, what individuals feel can be qualitatively different and still be parts of one and the same whole (Schmid 2009, 81-82). We can call this the jigsaw puzzle approach to token identity. Just as single pieces can differ greatly in size and form while remaining parts of the same jigsaw puzzle, different aspects of a feeling can differ widely while still being parts of the same experience. We would, of course, not talk about the different pieces of the puzzle as being token identical, and nor should we talk about the different feelings that constitute aspects of a shared emotion as being token identical either. Rather, the token identity pertains to that of which the different feelings are parts.

It is uncontroversial that different feelings of, say, joy can target the same object, say, the same musical performance. Schmid's proposal, by contrast, is that one and the same emotion can at one and the same time be felt differently by different individuals. But isn't there something quite problematic about this way of talking? Whereas it makes good sense to say that we must distinguish between an object and the experience(s) of the object, it is more questionable whether it makes sense to say that we must distinguish between an experience (the emotion) and the experiences of that experience. To insist upon that difference seems to commit one to the view that the relation between the emotion (the experience) and the way it feels (our awareness of it) amounts to an act-object relation. But does our first-person awareness of an experience really have such an actobject structure, are we really primarily (i.e. pre-reflectively) aware of our experiences as objects that we can adopt different perspectives on, or is this proposal not one that has been widely, and rightly, criticized? One of us has discussed this issue at length elsewhere (Zahavi 1999, 2005, 2014), and it would lead too far to develop the argument in any detail, so let us simply point out that the implication should be troublesome for Schmid, given that he himself assigns a quite central role to the notion of a non-objectifying pre-reflective self-awareness (2014b, 12-14). In short, we cannot see how Schmid's attempt to reconcile the token identity account with the difference condition allows him to preserve the notion of pre-reflective self-awareness.

We agree with Schmid that different individuals can share emotions although what they actually experience differ and that part of the reason for claiming that there is nevertheless a certain overarching unity to the different experiences is because they match or complement each other. We 
think Schmid is right when he argues that that which individuals think and feel when they do it together isn't independent of their relation $(2005,239)$. Finally, we would agree with the following statement:

In the case of shared feelings — shared grief, worries, and joys - there is a sense in which it is simply not the case that "I can't really know how you feel," because my feeling is your feeling, or rather: my feeling isn't really mine, and yours isn't yours, but ours. Shared feelings are conscious experiences whose subjective aspect is not singular ("for me"), but plural ("for us") (Schmid 2014a, 9).

We would agree with all of these claims, but we do not think accepting these claims commits one to the token identity account. ${ }^{8}$ In fact, we contend that the attempt to understand shared emotions on the basis of that notion is more confusing than helpful.

\section{Shared emotions}

In this section, we will present an account of shared emotions that does not rely on a token identity or fusional view of sharing, and that provides the ground for accepting the Socially Extended Emotion Thesis. Shared emotions, we shall argue, need not involve some kind of phenomenal fusion or breakdown of individual boundaries. At the same time, they surely involve more than synchronicity, mimicry, and aggregation, but also more, we will suggest, than mere social embeddedness or affective enhancement. On the account we will present, a necessary yet not sufficient condition for shared emotions is that the phenomenal character of a subject's emotional experience is socially extended in the sense of standing in a relationship of constitutive interdependence with the phenomenal character of another subject's emotional experience, without this entailing a breakdown of the individual boundaries of phenomenality. Social emotional extension, we propose, is a matter of a specific type of integration, where the inter-individual phenomenal differentiation, far from jeopardizing the integration, sustains it. On this view, what is decisive in order to understand shared emotions and the social emotional extension they arguably involve is to get right the appropriate sort of emotional integration, a point that we will come back to below. For the moment, it is worth noting that if the case for the Socially Extended Emotion Thesis can be made along the suggested lines, one should shun deflationary attempts to construe claims concerning extended emotions solely in

\footnotetext{
${ }^{8}$ See also Schmid (forthcoming). Incidentally, we are not convinced that this view is correctly ascribed to Scheler. For a different interpretation of the Scheler quote, see Zahavi 2014, 245, and Krebs 2015, 112-124.
} 
terms of (causal) coupling, or in terms of what is sometimes termed a 'scaffolding' or 'environmental support' of internal states (Sterelny 2010; Colombetti and Krueger 2014).

In prototypical cases, shared emotions involve the spatio-temporal proximity of two or more individuals who are perceptually co-present to each other. This normally happens in face-toface encounters, but there is of course room for less direct forms of perceptual or communicative interactions, involving, for example, temporal synchronicity but technological mediated spatial distance. Individuals who share emotions, in the sense we wish to investigate, will have, in virtue of the shared perceptual situation in which they partake, mutual awareness of their sharing. ${ }^{9}$

To better understand the character of shared emotions, it is instructive to consider the case of joint attention, a phenomenon that on many accounts of human ontogenetic development is related to early forms of affective sharing and mutual affect regulation (Hobson 2002, 2005; Hobson and Hobson 2011; Tomasello et al. 2005, 681; Reddy 2008). Triadic joint attention is thought to emerge between 9 and 12 months of age, when infants begin to engage in interactions with a caregiver and an object, either by following the adult's perceptual attention to the object, or by inviting the adult to share attention to the object. Before then, however, infants are already engaged in dyadic exchanges of attention with the caregivers. The developmental significance of joint attention has long been recognized (Bruner 1977, 287; Tomasello 1995, 2003; Baron-Cohen 1993), but for our present purposes the relevant aspect of joint attention is the interpersonal structure of sharing attention that takes place in it.

Even if developmentalists have primarily focused on joint attention in infancy, it obviously also plays a very important role in adult life. Consider the following example by John Campbell: "Suppose you are sitting on a park bench watching a swan, and someone comes to sit beside you. Perhaps there is some rudimentary conversation. So you shift from solitary attention to the swan, through a condition in which both you and your neighbor are coincidentally watching the swan, to full joint attention" (Campbell 2005, 287). According to the relational approach to joint attention defended by Campbell, a description of the state of each subject engaged in joint attention necessarily involves the fact that she is co-attending with someone else. To put it differently, the three-place joint attention relation is primitive in the sense that it cannot be broken down into sim-

\footnotetext{
${ }^{9}$ By 'mutual awareness of sharing' we mean that the fact of sharing an experience is mutually manifest or 'out in the open' for the involved subjects. Such mutual manifestation might be established, for example, by a "sharing look" (Carpenter and Liebal 2011). Mutual awareness of sharing differs from having common knowledge about the shared experience, if one understands common knowledge as essentially involving iterative epistemic states (following Schiffer (1972) and, on one interpretation of his account, Lewis (1969).
} 
pler components. ${ }^{10}$ Furthermore, importantly, on this view, joint attention is conceived as an experiential relation, in the sense that it brings about a "shift" with respect to solitary attention, and should not be thought of primarily as a sub-personal phenomenon, "remote from consciousness" (Campbell 2011, 420). Although Campbell primarily thinks of the shift in question as a change in the functional role of the experience, insofar as being part of a joint attention relation opens up new action possibilities, the relational approach to joint attention is compatible with a focus on the distinctive experiential shift that is involved in the transition from, say, attending to a swan in solitude to the experience of attending to the swan together.

On a relational view of joint attention, the experiences one is having when jointly attending to an object depend for their very experiential nature on someone else. Insofar as each coattender is registered as a constituent of the other co-attender's experience, each subject is internal to the configuration of the other's experience. The dependence between the co-attenders' experiences is therefore not merely causal, but constitutive of the experiences themselves. As Campbell argues, "when there is another person with whom you are jointly attending to the thing, the existence of that other person enters into the individuation of your experience" (Campbell 2005, 288; see also Hobson and Hobson 2011, 129). ${ }^{11}$ Importantly, the co-attender is not registered in the experience in the same way as the object that is the focus of attention (Campbell 2011, 419), but rather as a co-attender, that is, as a subject of experience (Eilan forthcoming).

We contend that the relational structure highlighted by this approach to joint attention is illuminating for understanding shared emotions. The idea of linking joint attention and shared emotions shouldn't be very surprising, especially if one considers that joint attention situation are often loaded with emotional value and significance (Hobson 1993; Carpenter and Liebal 2011). ${ }^{12}$ This

\footnotetext{
${ }^{10}$ This relational approach stands in contrast to the reductionist approach advocated by Peacocke (2005). According to Peacocke, it would be possible to characterize each subject's psychological state in joint attention independently of the fact that she is co-attending with someone else, by appealing to what he terms ascriptive interpersonal selfconsciousness, i.e., "awareness that one features, oneself, in someone else's consciousness" (Peacocke 2014). The contrast between Peacocke's and Campbell's accounts of joint attention is rooted in the contrast between a representationalist and a relationalist view of perceptual experience. It is worth noting that in spite of their contrasting accounts of joint attention, both Peacocke and Campbell concur in thinking of joint attention as more primitive than common knowledge (see previous footnote) (Campbell, 2005, 295; Peacocke, 2005, 299), and as a personal-level phenomenon (Campbell, 2011, 416; Peacocke, 2005, 301).

${ }^{11}$ One of the supporting ideas of Campbell's account of joint attention is that unless we think of the latter in relational terms, as a primitive relation, we would have a hard time making sense of the idea that subjects can be engaged in it without entertaining states of implausible complexity. A further motivation is a relational, acquaintance-based view of perceptual experience (of which the relational approach to joint attention is an extension, see Campbell 2002). For a more detailed discussion of Campbell's relational approach to joint attention, vis-à-vis other approaches to it, see León 2016.

${ }^{12}$ To be clear, the idea here is not that all instances of joint attention involve an affective component, but that they often do (as highlighted by developmental research, see Hobson 2002).
} 
doesn't mean that there are no significant differences between the two phenomena. Joint attention, at least on a 'rich' understanding of it, requires the coordinated and mutually aware focus of attention on a common object, but its "reference-securing role" (Eilan forthcoming) does not necessarily translate into the deeper synchronic and diachronic integration that is distinctive of shared emotions, an integration that is linked to a deeper appreciation of and an identification with other subjects' emotional perspectives and appraisals. The joint attention relation may indeed be plausibly construed, at a basic level, as providing the ground for an increasingly complex understanding of perspectivalness (Campbell 2011, 425; Moll and Meltzoff 2011; Moll 2012), which would eventually involve others' emotional focus and appraisal. If this is so, however, there would be reasons to think that the sharing of emotions is more demanding than joint attention, at least so characterized.

On the current proposal, shared emotions have a similar relational structure as joint attention. Let us now consider two specific requirements that any theory of shared emotions must accommodate:

(i) Reciprocal Other-awareness;

(ii) Integration

(i) A plurality of individuals might be aware of each other's emotions in many different ways. Consider the case of three frustrated spies who, completely unbeknownst to each other, are tracking each other's emotional expressivity and movements so as to find out where the other two are heading. There is a rather obvious difference between the awareness each spy has of the other two spies' frustration, and the reciprocal awareness involved in the case of, say, three spies who meet after a failed mission and share with each other their frustration. Or consider a situation where one is part of a winning curling team. The joy and pride one feels with one's teammates when realizing that victory is at hand is not simply individual joy and pride, nor is it simply a joy and pride that is causally dependent upon the bodily proximity of certain other actors. It is a joy and pride that is felt together with others, as one that we are having. In other words, I experience the joy and pride not simply as mine but as ours. A requirement for this kind of experience to occur is that I am aware of not being the only one who feels this way, but also aware that my team-colleagues feel the same way. In other words, I experience - and ipso facto I am aware of - the joy not as mine (alone) but as the joy of (all of) us. Accordingly, we hold that shared emotions must involve awareness of the 
emotional interpersonal interaction, that is, of the fact that each individual is affectively and experientially influencing the other.

But why must the other-awareness be reciprocal? Consider again the situation in Scheler's example, where I am observing a couple of grieving parents from a distance. I realize that they are grieving because of their dead son; I am also saddened by his death. The parents, however, remain unaware of both my presence and my emotional state. In such a situation, it does not seem appropriate to speak of me as sharing the grief of the parents. The felt grief is not given as our grief; it is not one we are feeling together. We consequently hold that it is counterintuitive to call a felt emotion 'shared' unless the subject of the experience is also aware of the presence and participation of others and vice-versa (see Zahavi 2015, Zahavi \& Rochat 2015). ${ }^{13}$

The Reciprocal Other-awareness Condition consequently holds that there must be a plurality of individuals engaged in shared emotion and an experienced differentiation between them (in this sense it fits our previous criticism of fusional and token-identity accounts). The condition also captures the idea that these individuals must be reciprocally aware of each other. The condition thus excludes cases in which an individual allegedly shares emotions with illusory others. Notice, furthermore, that the other-awareness to which this condition refers is by no means identical to Schmid's difference condition discussed above, although Schmid's point about the differences in individuals' fine-grained phenomenology of shared emotions may be a result of the Reciprocal Other-awareness Condition. The other-awareness component involved in this condition is also meant to block what we have called the jigsaw-puzzle approach and which arises, in the first place, from Schmid's attempt to combine a token-identity model of shared emotions with his difference condition.

Importantly, the Reciprocal Other-awareness Condition is not sufficient for shared emotions. After all, it is also met by all kinds of antagonistic relationships. In short, being aware of the other's emotion, and being aware of the other as emotionally interacting with oneself, might be necessary, but not sufficient for shared emotion. What more is needed? Not surprisingly, this questions points to the issue of togetherness, i.e., the kind of integration that is required by shared emotions.

\footnotetext{
${ }^{13}$ Notice that there is nothing in this requirement that rules out mistakes. I might believe that others are feeling like me and that we are having a shared emotion, but be mistaken about what they feel, and consequently be mistaken about there actually being a shared emotion. Other possible mistakes include what might be called 'collective emotions-inthe-vat scenarios' (cf. Schmid 2003), or various real-life cases of, say, solitary terrorist perpetrators, who, due to some psycho-pathological or ideological delusions, affectively identify with an imaginary group of collaborators or fellow travelers (or 'fellow-feelers').
} 
(ii) As we have already emphasized, and as most theorists would readily agree, shared emotions must be distinguished from emotional contagion, as well as from any similar more or less automatic or non-intentional forms of affective mimicry. ${ }^{14}$ One way to mark this difference is by pointing to the first-person plural character of the emotion, i.e., a shared emotion is an emotion that is experienced as ours, as one that we are having. The integration required here goes beyond not only summation or aggregation but also beyond cases of mere coupling or co-regulation. What is emotional integration? As suggested above, varieties of integration are closely linked to varieties of togetherness. One of the difficulties in fleshing out the required integration is that the depth or tightness of integration may well differ from case to case. One might share with another passer-by the delight of witnessing a violinist playing on the street, and a sharing look and a smile might make it transparent that the delight is shared. But, arguably, such sharing delivers only a quite ephemeral form of integration. Contrast this example with the kind of integration that can be found in the case of a romantic couple or a couple of friends in which the partners' tight integration and fully unified appraisal of, say, a happiness-inducing situation would make it possible and appropriate for them to articulate the experience in 'we' terms. ${ }^{15}$ What marks the difference between these two ranges of cases?

Identification makes a difference. To feel an emotion not simply as one's own but as ours, requires that one identifies with the other(s) in order to experience oneself as one of us, where the latter expression is understood in non-distributive terms. This identification might seem to be in tension with the Reciprocal Other-awareness Condition and its entailed preservation of a self-other difference. In fact, however, it simply modifies it in the following way. A self-other difference is indeed required, but if it is too salient, it will impede the feeling of togetherness. The difference between self and other has to be maintained, but similarities have to be accentuated, while individual differences are de-emphasized. Second-person engagement might here play a crucial role. By experiencing oneself through the eyes of the other, by incorporating the other's perspective on one-

\footnotetext{
${ }^{14}$ This is not to rule out that affective mimicry may be concomitantly present in shared emotions. Indeed, there might be good empirical reasons to think that processes of interpersonal synchronization and attunement greatly facilitate emotional integration and interpersonal identification in cases of shared emotions involving the co-presence of the participating individuals (see Hatfield et al. 2014; Salmela \& Nagatsu 2016a, 2016b). Moreover, we concede that affective mimicry and emotional contagion may be genetic or developmental precursors to shared emotions. And notice that also classical phenomenologists such as Scheler (2008), Walther (1923) or Stein (1922) would readily accept this. But our point is that processes of affective mimicry and emotional contagion do not constitute a necessary requirement for and certainly do not in and of themselves amount to emotional sharing.

${ }^{15}$ One consequently has to allow for a certain continuum in the degrees of sharedness, as also suggested by other authors (Salmela 2012, 2014; Salmela and Nagatsu 2016).
} 
self, one can come to see oneself as fundamentally like the other (for a fuller account, see Zahavi 2016).

The idea that interpersonal and reciprocal identification might be of relevance for understanding integration can be approached indirectly, making reference once again to developmental considerations, and to what we said above about joint attention. Peter and Jessica Hobson have argued that a propensity to identify with the attitudes of other people is critical for intersubjective engagement, and that the lack of this propensity is a crucial part of what explains the limited intersubjective experience of children with autism. Here the idea of identification does not primarily refer to imitation or alignment, but rather to a sort of assimilation of the other's perspective, which is still registered as another's perspective. As they put it, “one individual is motivated both to engage with others and to alter in motivation toward the world related to by the other. Through others, and in virtue of identification, a person is 'moved' in orientation-a motivational and emotional as well as cognitive process" (Hobson \& Hobson 2011, 130). According to them, it is in the context of joint attention that the intersubjective deficit of children with autism becomes first evident. They also relate the concept of 'identifying-with' to Merleau-Ponty's notion of mimesis (mimique): "Mimesis is the ensnaring of me by the other, the invasion of me by the other, it is that attitude whereby I assume the gestures, the conducts, the favourite words, conducts or facial expressions as my own (...) I live in the facial expressions of the other, as I feel him living in mine" (quoted in Hobson \& Hobson 2011, 130). Importantly, 'identifying-with' is not understood as the outcome of a process of personal-level simulation, via, for example, imaginative role-taking, but rather as providing the intersubjective ground for the possibility of such role-taking (Hobson \& Hobson 2011, 131).

Notice that while shared emotions require integration, this is compatible with there being, at least within some limits, space for individual differences between the felt emotions. As already mentioned, those differences do not prevent the feeling of togetherness. The integration of emotional experiences is fully consistent with there being complementarity between them, and sharing emotions might often be more an issue of an overarching emotional integration, than of a simple mirroring full matching between emotional experiences. As indicated above, we agree with Schmid that different individuals can share emotions although what they actually experience differs at the level of their fine-grained phenomenology. In this sense, the rapist example discussed above should not suggest that shared emotions simply involve matching or overlapping emotions that become internally related. What the example ought to show is that coupling and co-regulation are insufficient for shared emotion. The rapist and the victim are, on a standard reading of the concept of 
coupling, and especially on a causal one, clearly coupled, and they are also-even if only inversely-co-regulating their affects. And yet, it would be wrong to say that they share the same emotion, since their affects, sexual excitement and terror, are clearly opposed. Compare by contrast, a case where you become aware of my mortification over an unjust treatment I have been subjected to by a neighbor, who, say, has greeted me with a racial slur. As a result of this you feel distressed and upset about the happening. In order for you and me to engage in shared emotion, you do not necessarily need to feel humiliated and mortified, like I do, rather it would be sufficient if our respective complementary emotions converge in, say, an overarching shared feeling of anger about the event. Such emotional convergence is foreclosed in the rapist case. ${ }^{16}$

In an important recent account of shared emotions (Salmela \& Nagatsu 2016a, 2016b; cf. Salmela 2012), emotional convergence has been spelled out in terms of a "convergence" or “overlapping of concerns". 'Concern' is a complex technical notion in this context (see Roberts 2003; Helm 2008), but refers, roughly, to both cognitive and conative dimensions of emotions, and more precisely to the evaluative or appraisal component of emotions. On this account, shared emotions are "a matter of appraising the particular object of emotion similarly with other people on the basis of concerns that can be shared to a varying extent" (Salmela \& Nagatsu 2016a, 9). We believe that highlighting the importance of shared concern is justified, but we also want to insist that such a focus on shared concern has to be complemented by our account of reciprocal other-awareness and integration in order to amount to a satisfactory theory of emotional sharing. ${ }^{17}$

Given our account of the two conditions that have to be met in order for an emotion to be shared, shared emotions (and on our account they always come in the plural) are dynamic and relational phenomena which are constitutively dependent upon the right kind of intersubjective integration. Insofar as the participating individual's shared emotion incorporate the emotion(s) of the other participant(s) and exist only in its relationship with the latter, the emotion must be characterized in transactional terms (cf. Neisser 1976, 11), rather than lending itself to an exhaustive characterization in terms of processes and mechanisms located inside the physical boundaries of the

\footnotetext{
${ }^{16}$ What about the case of a consenting sadomasochist couple in which both parties gain pleasure from their interaction and co-regulate their pleasure, even if they draw pleasure from opposite actions within their interaction? One way of marking the difference between this case and the rapist case is by saying that emotional convergence, understood as an overarching integration of complementary emotional experiences, is not foreclosed in the former case. (Thanks to an anonymous reviewer for pressing this point).

${ }^{17}$ Salmela and Nagatsu talk about "mutual awareness" of shared emotional appraisal and affective experience among the participants in a shared emotion (Salmela and Nagatsu 2016a, 9; Salmela and Nagatsu 2016b, 36, 40), but leave the notion of mutual awareness unspecified. Likewise, as previously suggested, their reference to processes of interpersonal affective synchrony differs from what we mean by emotional integration (see above footnote 13).
} 
individual in question. And yet, even so, there is no breakdown of the boundaries of individual phenomenality. In accordance with conditions (i) and (ii), integration presupposes a preservation of the interpersonal differentiation, and the former could consequently not happen without the latter.

We have so far elaborated on the claim that shared emotions are socially extended emotions, but it is worth pointing out that there might also be more anonymous and normatively bounded forms of socially extended emotions, the investigation of which goes beyond the scope of this paper. These cases, which one might want to group under the label of collective emotions, occur independently of bodily interaction and interpersonal perceptual contact (see Szanto 2015). The interpersonal affective contact, partly because of the larger number of involved individuals, will typically be mediated, for example through complex technological scaffolding, (e.g., internet platforms, social media, television shows, broadcasting, etc.), and mechanisms of cultural and group identification (rituals, traditions or ceremonial practices, etc.). Given that a relation to specific others is unimportant for collective emotions, they harbor a certain degree of anonymity. In fact, one might experience collective emotions even if there is no reciprocal other-awareness of the sort discussed above. Whether or not the Integration Condition spelled out for shared emotions is continuous with the integration required by collective emotions remains here as an open question.

\section{Conclusion}

We have investigated the Extended Emotions Thesis, by exploring and defending the claim that shared emotions are socially extended emotions. In doing so, we have built our argument on the hypothesis that resources from discussions on joint attention and collective intentionality can productively be employed in the Extended Mind debate. As we have seen, one way to conceive of shared emotions qua socially extended emotions is to argue that they involve some kind of phenomenal fusion or breakdown of individual boundaries. This implication might seem so egregious that it makes the very notion of shared emotions lose its attraction. As we have argued, however, this skepticism is unwarranted, if only one bids farewell to various fusional accounts. One can reject these accounts without denying the possibility of genuine emotional sharing. We need to avoid both the Scylla of an 'all-too much' or 'all-too tight' affective integration (fusion, token-identity or phenomenal subject-identity) and the Charybdis of the 'too little' or 'too loose' one (synchronicity, mimicry, aggregation, summation, mere social embeddedness or affective enhancement). Getting 
this right shows that cases of emotional sharing are indeed highly relevant for the debate on extended emotions.

After criticizing token-identity and fusional views of shared emotions, we motivated an account of shared emotions based on the conditions of (i) Reciprocal Other-awareness, and (ii) Integration. In particular, consideration of (ii) led us to the idea that shared emotions are socially extended emotions. Recall that in our initial characterization of the Extended Emotion Thesis we stressed the difference between mere coupling and more robust forms of integration. Some authors have suggested that one should only speak of proper extension in those cases where a subject would not have had the same emotional experience if the emotion in question were not robustly and appropriately integrated with some extra-organismic vehicle. Such a counterfactual construal, however, seems to fall short of capturing the full-blown constitutive integration we find in genuinely extended shared emotions, which goes beyond social situatedness or embeddedness. Indeed, instead of referring merely to coupling or various forms of 'scaffolding', we think the Socially Extended Emotion Thesis should primarily be construed in terms of a constitutive integration of the experiences of different individuals. 


\section{References}

Adams, F., \& Aizawa, K. (2008). The Bounds of Cognition. London: Wiley-Blackwell.

Damasio, A. (1994). Descartes' Error. Emotion, Reason, and the Human Brain. London: Penguin.

Cash, M. (2013). Cognition without borders: "third wave" socially distributed cognition and relational autonomy. Cognitive Systems Research, 25-26, 61-71.

Baron-Cohen, S. (1993). From attention-goal psychology to belief-desire psychology. In S. BaronCohen, H. Tager-Flusberg \& D. Cohen (eds.): Understanding other minds: Perspectives from autism (pp. 59-82). Oxford: Oxford University Press.

Bruner, J. (1977). Early social interaction and language acquisition. In H. R. Schaffer (ed.) Studies in Mother-Infant Interaction (pp. 271-289). New York: Academic Press.

Campbell, J. (2005). Joint Attention and Common Knowledge. In N. Eilan, C. Hoerl, T. McCormack, and J. Roessler (eds.): Joint Attention: Communication and Other Minds. Issues in Philosophy and Psychology (pp. 287-297). New York: Oxford University Press.

Campbell, J. (2011). An Object-Dependent Perspective on Joint Attention. In A. Seemann (ed.), Joint Attention: New Developments in Psychology, Philosophy of Mind, and Social Neuroscience (pp. 415-430). Cambridge and London: The MIT Press.

Carpenter, M., \& Liebal, K. (2011). Joint Attention, Communication, and Knowing Together in Infancy. In A. Seemann (ed.): Joint Attention: New Developments in Psychology, Philosophy of Mind, and Social Neuroscience (pp. 159-181). Cambridge, MA: The MIT Press.

Carter, A. J., Gordon, E. C., \& Palermos, O. S. (2016). Extended Emotion. Philosophical Psychology, 29(2), 198-217.

Clark, A. (2008) Supersizing the Mind. Embodiment, Action and Cognitive Extension. Oxford: Oxford UP.

Clark, A. (2009). Spreading the Joy? Why the Machinery of Consciousness is (Probably) Still in the Head. Mind, 118(472), 963-993.

Clark, A. (2010). Coupling, Constitution and the Cognitive Kind. A Reply to Adams and Aizawa.' The Extended Mind. In R. Menary (ed.) (pp. 81-100). Cambridge, MA: MIT Press.

Clark, A., \& Chalmers, D. (1998). The Extended Mind. Analysis, 58(1), 7-19.

Colombetti, G. (2014). The Feeling Body. Affective Science Meets the Enactive Mind. Cambridge, MA: MIT Press.

Colombetti, G., \& Roberts, T. (2015). Extending the extended mind: the case for extended affectivity. Philosophical Studies, 172(5), 1243-1263.

Colombetti, G., \& Krueger, J. (2015). Scaffoldings of the Affective Mind. Philosophical Psychology, 28(8), 1157-1176.

De Jaegher, H. (2013). Rigid and fluid interactions with institutions. Cognitive Systems Research, 25(25-26), 19-25.

de Rivera, J., \& Páez, D. (2007). Emotional Climate, Human Security, and Cultures of Peace. Journal of Social Issues, 63(2),233-253.

Eilan, N. (forthcoming). Joint attention and the second person. http://www2.warwick.ac.uk/fac/soc/philosophy/people/eilan/jasphum.pdf. Accessed 28 March 2016.

Gallagher, S., \& Crisafi, A. (2009). Mental Institutions. Topoi, 28(1), 45-51. 
Griffiths, P. E., \& Scarantino, A. (2009). Emotions in the wild: The situated perspective on emotion. In P. Robbins, P., \& M. Aydede (eds.): The Cambridge Handbook Of Situated Cognition (pp. 437453). Cambridge: Cambridge UP.

Hatfield, E., Carpenter, M., \& Rapson, R. L. (2014). Emotional contagion as a precursor to collective emotion. In C. von Scheve \& M. Salmela (eds.): Collective emotions (pp. 108-122). Oxford: Oxford University Press.

Hobson, R. P. (1993). Autism and the Development of Mind. Hove: Psychology Press.

Hobson, R. P. (2002). The Cradle of Thought. London: Macmillan.

Hobson, R.P. (2005). What Puts the Jointness into Joint Attention? In N. Eilan, C. Hoerl, T. McCormack, and J. Roessler (eds.): Joint Attention: Communication and Other Minds. Issues in Philosophy and Psychology (pp. 185-204). New York: Oxford University Press.

Hobson, R. P., \& Hobson, J. (2011). Joint Attention or Joint Engagement? Insights from Autism. In A. Seemann (ed.): Joint Attention: New Developments in Psychology, Philosophy of Mind, and Social Neuroscience (pp. 115-136). Cambridge, MA: MIT Press

Horgan, T., Kriegel, U. (2008). Phenomenal Intentionality Meets the Extended Mind. The Monist, 91(2), $347-373$.

Huebner, B. (2011). Genuinely collective emotions. European Journal for Philosophy of Science, 1(1), $89-118$.

Hurley, S. L. (2010). Varieties of externalism. In R. Menary (ed.): The Extended Mind (pp. 101-153). Cambridge, MA: MIT Press.

Husserl, E. (1952). Ideen zu einer reinen Phänomenologie und phänomenologischen Philosophie. Zweites Buch. Phänomenologische Untersuchungen zur Konstitution. E. M. Biemel. Husserliana 4. Den Haag: Martinus Nijhoff.

Husserl, E. (1973). Zur Phänomenologie der Intersubjektivität I. Texte aus dem Nachlass. Erster Teil. 1905-1920. Ed. I. Kern. Husserliana 13. Den Haag: Martinus Nijhoff.

Husserl, E. (1976). Ideen zu einer reinen Phänomenologie und phänomenologischen Philosophie. Erstes Buch: Allgemeine Einführung in die reine Phänomenologie. Ed. K. Schuhmann. Husserliana 3, 12. Den Haag: Martinus Nijhoff.

Kagan, A., \& Lassiter, C. (2013). The coupling-constitution fallacy: Much ado about nothing. Pragmatics \& Cognition, 21(1), 178-192.

Kiverstein, J., \& Farina, M. (2012). Do sensory substitution devices extend the conscious mind? In F. Paglieri (ed.): Consciousness in Interaction: The role of the natural and social context in shaping consciousness (pp. 19-40). Amsterdam: John Benjamins.

Kirchhoff, M. D. (2012). Extended cognition and fixed properties: steps to a third-wave version of extended cognition. Phenomenology and the cognitive sciences, 11(2), 287-308.

Krebs, A. (2015). Zwischen Ich und Du. Eine dialogische Philosophie der Liebe. Berlin: Suhrkamp.

Kriegel, U. (2009). Subjective Consciousness: A Self-Representational Theory. Oxford and New York: Oxford University Press.

Krueger, J. (2011). Extended cognition and the space of social interaction. Consciousness and Cognition, 20(3), 643-657.

Krueger, J. (2013). Merleau-Ponty on shared emotions and the joint ownership thesis. Continental Philosophy Review 46(4), 509-531.

Krueger, J. (2014). Varieties of extended emotions. Phenomenology and the Cognitive Sciences, 13(4) (2014), 533-555. 
Krueger, J. (2016). The Affective 'We': Self-regulation and Shared Emotions. In T. Szanto, \& D. Moran (eds.): The Phenomenology of Sociality: Discovering the 'We' (pp. 263-277). London, New York: Routledge.

Krueger, J., \& Szanto, T. (2016). Extended Emotions. Philosophy Compass 11/12, 2016, 863-878.

León, F. (2016). Shared experiences and other minds. PhD Thesis, Faculty of Humanities, University of Copenhagen.

León, F., \& Zahavi, D. (2016). Phenomenology of experiential sharing: The contribution of Schutz and Walther. In A. Salice \& H. B. Schmid (eds.): The Phenomenological Approach to Social Reality: History, Concepts, Problems (pp. 219-234). Cham: Springer International Publishing.

Lewis, D. K. (1969). Convention. Cambridge, MA, USA: Harvard University Press.

Loughlin, V. (2013). Sketch This: Extended Mind and Consciousness Extension. Phenomenology and the Cognitive Sciences, 12(1), 41-50.

Menary, R. (2007). Cognitive Integration: Mind and Cognition Unbounded: Attacking the Bounds of Cognition. Basingstoke: Palgrave Macmillan.

Menary, R. (2010). Cognitive Integration and the Extended Mind. In R. Menary (ed.): The Extended Mind (pp. 227-243). Cambridge, MA: MIT Press.

Merleau-Ponty, M. (1964). The Primacy of Perception. Evanston: Northwestern University Press.

Moll, H. (2012). Von der Teilnahme an gemeinsamer Aufmerksamkeit zum Begriff von Perspektiven: Stufen einer Entwicklung. In P. Stekeler-Weithofer (ed.): Wittgenstein: Philosophie und Wissenschaft (pp. 251-267). Hamburg: Felix Meiner

Moll, H. \& Meltzoff, A. (2011). Joint Attention as the Fundamental Basis of Understanding Perspectives. In A. Seemann (ed.): Joint attention: New Developments in Psychology, Philosophy of Mind and Social Neuroscience (pp. 393-413). Cambridge and London: The MIT Press .

Neisser, U. (1976). Cognition and Reality. San Francisco: W.H. Freeman and Company.

Parkinson, B., Fischer, A. H., Manstead, A. S. R. (2005). Emotion in Social Relations. Cultural, Group, and Interpersonal Processes. New York: Psychology Press.

Peacocke, C. (2005). Joint Attention: Its Nature, Reflexivity and Relation to Common Knowledge. In N. Eilan, C. Hoerl, T. McCormack, and J. Roessler (eds.): Joint Attention: Communication and Other Minds. Issues in Philosophy and Psychology (pp. 287-297). New York: Oxford University Press.

Reddy, V. (2008). How Infants Know Minds. Cambridge, Mass.: Harvard University Press.

Roberts, T. (2015). Extending Emotional Consciousness. Journal of Consciousness Studies, 22(3-4), $108-128$.

Rowlands, M. (2003). Externalism: Putting Mind and World Back Together Again. Chesham: Acumen.

Rowlands, M. (2010). The New Sciences of the Mind. From Extended Mind to Embodied Phenomenology. Cambridge, MA: MIT Press.

Rupert, R. D. (2009). Cognitive Systems and the Extended Mind. Oxford: Oxford UP.

Salmela, M. (2012). Shared emotions. Philosophical Explorations, 15(1), 33-46.

Salmela, M. (2014). The Functions of Collective Emotions in Social Groups. In A. Konzelmann Ziv, \& H. B. Schmid (eds.): Institutions, Emotions, and Group Agents (pp. 159-176). Dordrecht: Springer.

Salmela, M., \& Nagatsu, M. (2016a). How Does it Really Feel to Act Together? Shared Emotions and the Phenomenology of We-agency. Phenomenology and the Cognitive Sciences, 1-22.

Salmela, M., \& Nagatsu, M. (2016b). Collective Emotions and Joint Action. Journal of Social Ontology, 2(1), 33-57. 
Scheler, M. (2008). The Nature of Sympathy. London: Transaction Publishers.

Scherer, K. R. (2005). What are emotions? And how can they be measured? Social science information, 44(4), 695-729.

Schiffer, S. (1972) Meaning. Oxford: Clarendon Press.

Schmid, H. B. (2003). Can brains in vats think as a team?, Philosophical Explorations, 6(3), 201-217.

Schmid, H. B. (2005). Wir-Intentionalität: Kritik des ontologischen Individualismus und Rekonstruktion der Gemeinschaft. Freiburg: Karl Alber.

Schmid, H. B. (2009). Plural Action. Essays in Philosophy and Social Science. Dordrecht: Springer.

Schmid, H. B. (2014a). The feeling of being a group: corporate emotions and collective consciousness. In C. v. Scheve, \& M. Salmela (eds.): Collective emotions. Perspectives from Psychology, and Sociology, (pp. 3-16). Oxford: Oxford UP.

Schmid, H.B. (2014b). Plural self-awareness. Phenomenology and the Cognitive Sciences, 13(7), 7-24.

Schmid, H. B. (forthcoming). Collective Emotions: Phenomenology, Ontology, and Ideology What Should We Learn From Max Scheler's War Propaganda? Max Scheler Jahrbuch. https://www.academia.edu/17469415/Collective_Emotions_phenomenology_Ontology_and_Ideo$\log$.

Schutz, A. (1967). The phenomenology of the social world. Evanston: Northwestern University Press.

Slaby, J. (2014). Emotions and the extended mind. In C. v. Scheve \& M. Salmela (eds.): Collective emotions. Perspectives from Psychology, and Sociology, (pp. 32-46). Oxford: Oxford UP.

Stein, E. (1922). Beiträge zur philosophischen Begründung der Psychologie und der Geisteswissenschaften. Edith Stein Gesamtausgabe, Vol. 6. Wien, Basel, Köln: Herder 2010.

Stephan, A., Walter, S., \& Wilutzky, W. (2014). Emotions beyond brain and body. Philosophical Psychology, 27(1), 65-81.

Sullivan, G. B. (2015). Collective emotions. Social and Personality Psychology Compass, 9(8), 383393.

Sutton, J. (2010). Exograms and Interdisciplinarity: History, the Extended Mind and the Civilizing Process. In R. Menary (ed.), The Extended Mind (pp. 189-225). Cambridge, MA: MIT Press.

Szanto, T. (2015). Collective Emotions, Normativity and Empathy: A Steinian Account. Human Studies $38 / 4,503-527$.

Szanto, T. (2016a). Collectivizing Persons and Personifying Collectives: Reassessing Scheler on Group Personhood. In T. Szanto \& D. Moran (eds.): Phenomenology of Sociality: Discovering the We (pp. 296-312). New York: Routledge.

Szanto, T. (2016b). Husserl on Collective Intentionality. In A. Salice \& H. B. Schmid (eds.): The Phenomenological Approach to Social Reality: History, Concepts, Problems (pp. 145-172). Cham: Springer.

Szanto, T. (forthcoming). The Phenomenology of Shared Emotions: Reassessing Gerda Walther. Forthcoming In S. Luft \& R. Hagengruber (eds.): Women Phenomenologists on Social Ontology. Dordrecht: Springer.

Tollefsen, D. P. (2006). From extended mind to collective mind. Cognitive Systems Research, 7(2/3), $140-150$.

Tomasello, M. (1995). Joint attention as social cognition. In C. Moore \& P. Dunham (eds.): Joint Attention: Its Origins and Role in Development (pp. 103-130). Hillsdale, NJ: Erlbaum. 
Tomasello, M. (2003). The Key is Social Cognition. In D. Gentner \& S. Goldin-Meadow (eds.): Language in Mind. Advances in the Study of Language and Thought (pp. 47-57) Cambridge and London: MIT Press.

Tomasello, M., Carpenter, M., Call, J., Behne, T., and Moll, H. (2005). Understanding and sharing intentions: The origins of cultural cognition. Behavioral and Brain Sciences 28, 675-735.

von Scheve, C., \& Salmela, M. (eds.) (2014). Collective Emotions. Perspectives from Psychology, and Sociology. Oxford: Oxford UP.

Walther, G. (1923). Zur Ontologie der sozialen Gemeinschaften. In Jahrbuch für Philosophie und phänomenologische Forschung, 6, 1-158.

Ward, D. (2012). Enjoying the Spread: Conscious Externalism Reconsidered. Mind, 121(483), 731-751.

Wheeler, M. (2015). Extended Consciousness: An Interim Report. The Southern Journal of Philosophy, 53(S1), 155-175.

Wilson, R. A. (2004). Boundaries of the Mind: The Individual in the Fragile Sciences-Cognition. Cambridge: Cambridge UP.

Wilson, R. A. \& Clark, A. (2009). How to situate cognition: Letting nature take its course. In P. Robbins, P., \& M. Aydede (eds.): The Cambridge Handbook Of Situated Cognition (pp. 55-77). Cambridge: Cambridge UP.

Zahavi, D. (1999). Self-Awareness and Alterity: A Phenomenological Investigation. Evanston: Northwestern University Press.

Zahavi, D. (2005). Subjectivity and Selfhood: Investigating the first-person perspective. Cambridge, MA.: MIT Press.

Zahavi, D. (2014). Self and other: exploring subjectivity, empathy, and shame. Oxford: Oxford University Press.

Zahavi, D. (2015). You, Me, and We: The Sharing of Emotional Experiences. Journal of Consciousness Studies 22/1-2, 84-101.

Zahavi, D. (2016). Second-Person Engagement, Self-Alienation, and Group-Identification. Topoi doi:10.1007/s11245-016-9444-6

Zahavi, D., \& Kriegel, U. (2016). For-Me-Ness: What It Is and What It Is Not." In D.O. Dahlstrom, A. Elpidorou \& W. Hopp (eds.): Philosophy of Mind and Phenomenology: Conceptual and Empirical Approaches (pp. 36-53). London: Routledge.

Zahavi, D., \& Rochat, Ph. (2015). Empathy $\neq$ sharing: Perspectives from phenomenology and developmental psychology. Consciousness and Cognition 36, 543-553.

Zahavi, D. \& Salice, A. (2017). Phenomenology of the we: Stein, Walther, Gurwitsch. In J. Kiverstein (ed.): The Routledge Handbook of Philosophy of the Social Mind (pp. 515-527). New York: Routledge. 